\title{
Synthesis and conformational investigation of hetero-chiral sequential oligopeptides based on
} the $(\alpha \mathrm{Me})$ Aze/Ala dyad

\author{
Bruno Drouillat ${ }^{1}$, Cristina Peggion ${ }^{2}$, Barbara Biondi $^{2}$, Karen Wright ${ }^{1}$, François Couty ${ }^{1}$, Marco Crisma $^{2}$, \\ Fernando Formaggio ${ }^{2}$, Claudio Toniolo ${ }^{2}$
}

${ }^{1}$ Institute Lavoisier de Versailles, UMR CNRS 8180, Université de Versailles, France ${ }^{2} \mathrm{ICB}$, Padova Unit, CNR, Department of Chemistry, University of Padova, Italy

https://doi.org/10.17952/35EPS.2018.197

\section{Introduction}

Methylation at the $\mathrm{C} \alpha$-position of a Pro residue is known to lock the preceding tertiary amide $(\omega)$ torsion angle of the resulting ( $\alpha \mathrm{Me}$ )Pro (Fig. 1) residue to the trans disposition and to restrict the $\alpha, \psi$ surface mainly to the region where the 310-/ $\alpha$-helices are found [1]. Moreover, the known high propensity for $\beta$-turn formation of the Pro residue is further enhanced in peptides based on its $\mathrm{C} \alpha$-methylated derivative. A few years ago some of us developed a practical, multigram scale synthesis of both $(\alpha \mathrm{Me})$ Aze (Fig. 1) enantiomers [2]. This residue is characterized by a ring contraction (from five to four atoms) with respect to ( $\alpha \mathrm{Me})$ Pro. Herein, we discuss synthesis and conformational analysis of the following set of hetero-chiral sequential oligopeptides based on the -(S)-Ala-(R)-( $\alpha \mathrm{Me})$ Aze- dyad:

(a) Boc- $[(\mathrm{S})-\mathrm{Ala}-(\mathrm{R})-(\alpha \mathrm{Me})$ Aze $] \mathrm{n}-\mathrm{OMe}(\mathrm{n}=1-3)$

(b) Boc-[(S)-Ala-(R)-( $\alpha \mathrm{Me})$ Aze $] \mathrm{n}-(\mathrm{S})-$ Ala-OMe $(\mathrm{n}=1,2)$

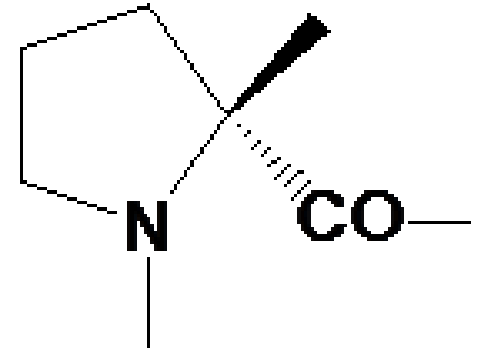

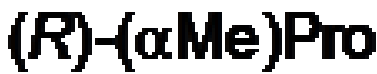

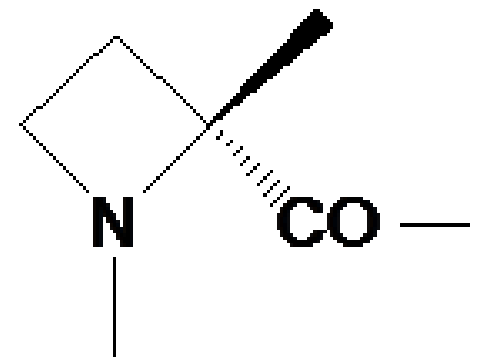

$(R)-(\alpha M e)$ Aze

Figure 1: Chemical structures of $(R)-(\alpha M e)$ Pro, left, and $(R)-(\alpha M e)$ Aze, right.

\section{Results and Discussion}

Peptide syntheses were achieved in acceptable yields by use of the HATU coupling reagent.

Results from our combined X-ray diffraction and solution studies of terminally protected, hetero-chiral sequential oligopeptides based on the -(S)-Ala-(R)- $(\alpha \mathrm{Me})$ Aze- dyad support the view that this type of oligopeptide sequence strongly favors folding of the main chain into turns. In particular, the occurrence of a type-II $\beta$-turnhas been unambiguously demonstrated for the $-(\mathrm{S})$-Ala- $(\mathrm{R})-(\alpha \mathrm{Me})$ Aze- sequence in the crystal state (Fig. 2$)$. This finding matches that published for the strictly related -(S)-Ala-(R)-( $\alpha$ Me)Pro- sequence [1] (Fig. 2). 

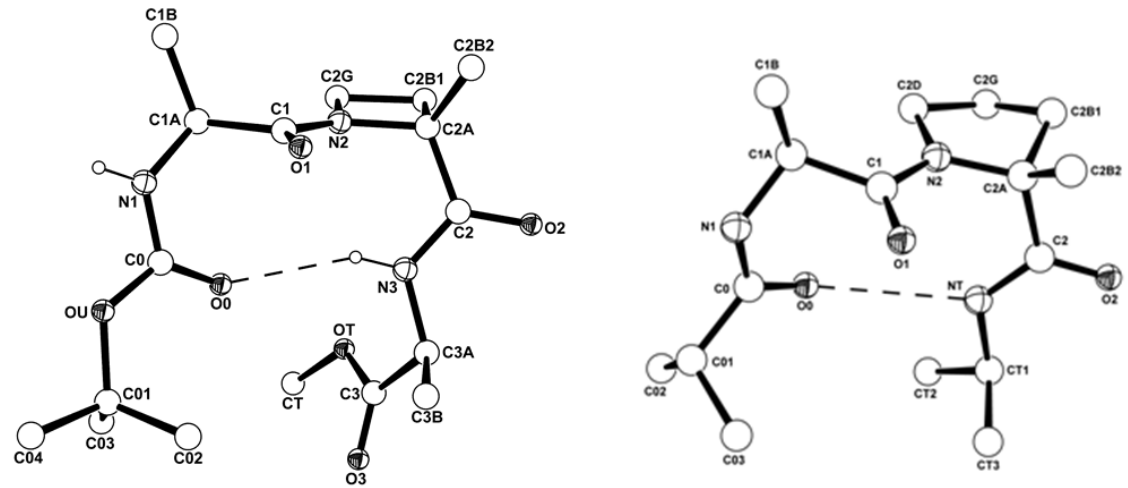

Figure 2:-Ray diffraction structures of the tripeptide ester Boc-(S)-Ala-(R)-(aMe)Aze-(S)-Ala-OMe (left) and the dipeptide alkylamide $\mathrm{Pr}$-CO-(S)-Ala-(R)-(aMe)Pro-NHiPr (right) [1]. In both peptides the tertiary amide (w) torsion angle is trans.

However, FT-IR absorption and 2D-NMR data provide evidence that in $\mathrm{CDCl} 3$ solution the tripeptide ester is mainly folded in a $\gamma$-turn conformation. As for its higher homologs, in solution they seem to be involved in conformational equilibria to which both $\beta$ - and $\gamma$-turn conformations may contribute. It is worth recalling here that the $\gamma$-turn promoting ability of $(\alpha \mathrm{Me})$ Aze was previously documented by us with the crystal structure of the homo-chiral tetrapeptide Boc-[(S)-MeAze-(S)-Ala]2-OMe [3]. In any case, even if $\beta$-turns may prevail over $\gamma$-turns in the longest hetero-chiral oligomers, the resulting overall structure would be a "flat" $\beta$-turn ribbon [4], distinct from the (helical) $\beta$-turn ribbon spiral typical of sequential oligopeptides based on the Aib-Pro- dyad [5].

\section{References}

[1] Moretto, A.; Terrenzani, F.; Crisma, M.; Formaggio, F.; Kaptein, B.; Broxterman, Q. B.; Toniolo, C. Biopolymers 2008, 89, 465. DOI: 10.1002/bip.20839

[2] Drouillat, B.; Wright, K.; Marrot, J.; Couty, F. Tetrahedron: Asymmetry 2012, 23, 690. DOI: 10.1016/ j.tetasy.2012.05.006

[3] Crisma, M.; De Zotti, M.; Moretto, A.; Peggion, C.; Drouillat, B.; Wright, K.; Couty, F.; Toniolo, C. New J. Chem. 2015, 39, 3208. DOI: 10.1039/C4NJ01564A

[4] Hayward, S.; Leader, D. P.; Al-Shubailly, F.; Milner-White, E. J. Proteins: Struct., Funct., Bioinform. 2014, 82, 230. DOI: /10.1002/prot.24357

[5] Di Blasio, B.; Pavone, V.; Saviano, M.; Lombardi, A.; Nastri, F.; Pedone, C.; Benedetti, E.; Crisma, M.; Anzolin, M.; Toniolo, C. J. Am. Chem. Soc. 1992, 114, 6273. DOI: 10.1021/ja00042a001 